\title{
Application of Quantum Dots-Based Biotechnology in Cancer Diagnosis: Current Status and Future Perspectives
}

\author{
Chun-Wei Peng ${ }^{1}$ and ${\text { Yan } \mathrm{Li}^{1,2}}$ \\ ${ }^{1}$ Department of Oncology, Zhongnan Hospital of Wuhan University, No 169 Donghu Road, Wuchang District, Wuhan 430071, China \\ ${ }^{2}$ Hubei Key Laboratory of Tumor Biological Behaviors, Hubei Cancer Clinical Study Center, No 169 Donghu Road, Wuchang District, \\ Wuhan 430071, China
}

Correspondence should be addressed to Yan Li, liyansd2@163.com

Received 1 October 2009; Revised 15 December 2009; Accepted 20 January 2010

Academic Editor: Huisheng Peng

Copyright (c) 2010 C.-W. Peng and Y. Li. This is an open access article distributed under the Creative Commons Attribution License, which permits unrestricted use, distribution, and reproduction in any medium, provided the original work is properly cited.

The semiconductor nanocrystal quantum dots (QDs) have excellent photo-physical properties, and the QDs-based probes have achieved encouraging developments in cellular and in vivo molecular imaging. More and more researches showed that QDsbased technology may become a promising approach in cancer research. In this review, we focus on recent application of QDs in cancer diagnosis and treatment, including early detection of primary tumor such as ovarian cancer, breast cancer, prostate cancer and pancreatic cancer, as well as regional lymph nodes and distant metastases. With the development of QDs synthesis and modification, the effect of QDs on tumor metastasis investigation will become more and more important in the future.

\section{Introduction}

Cancer is a major public health problem in the world, and one in four deaths in the United States is due to cancer, with an estimated 1479350 new cancer cases and 562340 deaths from cancer expected in 2009 [1]. Although progress has been made in reducing incidence and mortality rates and improving survival, cancer still accounts for more deaths than heart disease in persons younger than 85 years of age [1]. One major challenge is how to diagnose cancer in early stage when curative treatment is possible. New technologies are required to dramatically improve the early detection and treatment of cancer, and fluorescent molecules can play a big role in this field $[2,3]$.

Nanotechnology is an emerging field that may have potentials to make paradigm changes in the detection, treatment, and prevention of cancer [4]. The development of biocompatible nanoparticles for molecular targeted diagnosis and treatment is an area of considerable interest. The basic rationale is that nanoparticles have unique structural and functional properties different from those of discrete molecules or bulk materials $[5,6]$. One of the most exciting advances in label technology is the development of quantum dots (QDs), a heterogeneous class of engineered nanoparticles with unique optical and chemical properties making them important nanoparticles with numerous potential applications ranging from medicine to energy $[7,8]$. Used as in vitro and in vivo fluorophores, QDs are intensely studied in molecular, cellular, and in vivo imaging due to their novel optical and electronic properties [9-11]. To be different from those reviews focusing on the basic mechanisms and development of QDs, this review focuses on recent application of QDs in cancer diagnosis, including early detection of primary tumor such as ovarian cancer, breast cancer, prostate cancer, and pancreatic cancer, as well as regional lymph nodes and distant metastases.

\section{QDs Properties}

QDs are nanocrystals composed of a semiconductor core including group II-VI or group III-V elements encased within a shell comprised of a second semiconductor material. A typical QD has a diameter ranging from 2 to $10 \mathrm{~nm}$ containing roughly 200 to 10,000 atoms, with size comparable to a large protein. In comparison with organic dyes and fluorescent proteins, QDs have unique optical and 

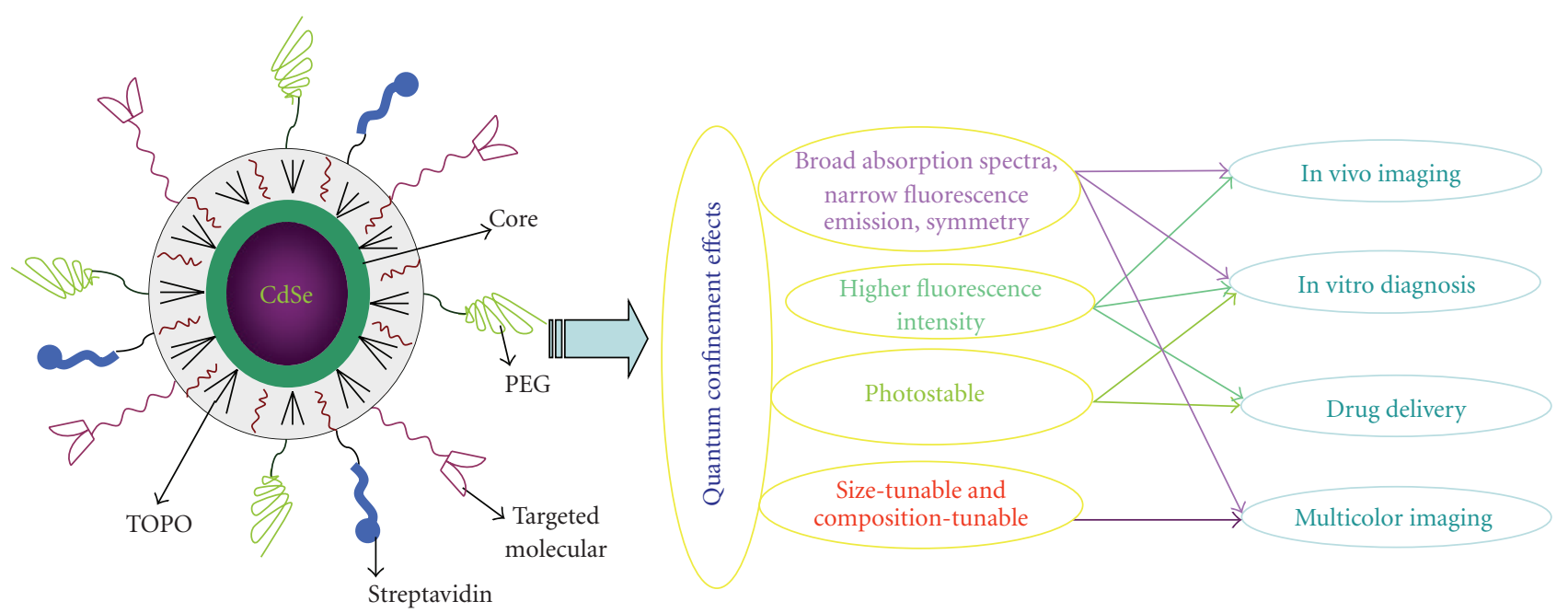

Figure 1: Properties of QDs. QDs are characterized with broad aborption spectra, size- and composition-tunable, narrow fluorescence emission, high levels of brightness and photostability. QDs can be used in in vitro and in vivo multicolor imaging and targeted drug delivery.

electronic properties such as size- and composition-tunable light emission, improved signal brightness, resistance to photobleaching and simultaneous excitation of multiple fluorescence colors. In addition, different colors of QDs can be simultaneously excited with a single light source, with minimal spectral overlapping, which provides significant advantages for multiplexed detection of target molecules [10, 12-15] (Figure 1). However, as QDs are hydrophobic by nature, it is necessary to solubilize QDs before application by surface modification with biofunctional molecules [16], because QDs have large surface areas for the attachment of such molecules. When conjugated with diagnostic (e.g., optical) and therapeutic (e.g., anticancer) agents, QDs can be used for cancer diagnosis and therapy with high specificity [17-19]. Significant research efforts have been focused on cancer early diagnosis with QDs [20]. As early as 2002, after overcoming the limitation in obtaining biocompatible nanocrystals, Dubertret [21] showed the potential to revolutionize biological imaging. In case of imaging probes, active targeting of cancer antigens (molecular imaging) has become an area of tremendous interest because of the potential to detect early stage cancers and their metastases [22-24]. Major recent developments in this regard are summarized in Table 1.

\section{QDs-Based Detection of Primary Tumor}

3.1. Ovarian Cancer. Ovarian cancer is the second mostcommon malignancy of the female genital tract and the leading cause of death from gynecological malignancies [33]. Carbohydrate antigen 125 (CA 125) is an epithelial antigen and a useful tumor marker in the detection and therapy of ovarian cancer [34-36]. The ability to visualize native processes occurring in living organisms is invaluable for clinical diagnostic applications, yet it remains elusive in practice due to conventional imaging limitations and the availability of suitable fluorescence markers. Because of their unique photophysical properties, QDs are promising fluorophores for in vivo fluorescence imaging and can overcome many shortcomings of conventional dyes. Wang et al. [37] used QDs with maximum emission wavelength $605 \mathrm{~nm}$ (QD605) to detect CA125 in ovarian cancer specimens of different types (fixed cells, tissue sections, and xenograft tumor) with high specificity and sensitivity. Comparison between QDs and fluorescein isothiocyanate (FITC) showed that QDs labeling signals were brighter, more specific and stable than those of FITC. In another study, Nathwani [38] synthesized biocompatible QDs coated with a natural protein silk fibroin (SF) and used such QDs conjugates as a fluorescent label for successful bioimaging HEYA8 ovarian cancer cells. The properties of QDs have opened new possibilities for advanced molecular and cellular imaging as well as for ultrasensitive bioassays and diagnostics of ovarian cancer.

3.2. Breast Cancer. Wu et al. [39] explored a new technology to label HER2 (human epidermal growth factor receptor 2, HER2) on breast cancer cell membrane, which is known as c-erbB-2 or HER2/neu and overexpressed in approximately $25-30 \%$ invasive breast cancer $[40,41]$ and plays an important role in breast cancer prognosis and treatment selection [42-45]. After that, several studies on the detection of HER2 for breast cancer diagnosis with QDs have completed [46, 47]. Yezhelyev et al. [25] reported the use of multicolor QDs for quantitative and simultaneous profiling of multiple biomarkers using intact breast cancer cells and clinical specimens and the comparison between the new QDsbased molecular profiling technology with standard western blotting and fluorescence in situ hybridization (FISH). The multicolor bioconjugates were used for simultaneous detection of the five clinically significant tumor markers, including HER2 (QD-HER2), ER (QD-ER), PR (QD-PR), EGFR (QD-EGFR), and mTOR (QD-mTOR), in breast cancer cells MCF-7 and BT474. A quantitative correlation 
TABLE 1: Application of QDs in molecular, cell, tissue, animal model cancer imaging (since 2007).

\begin{tabular}{|c|c|c|c|c|}
\hline Authors & QDs used & Major findings & Advantages & Problems \\
\hline \multicolumn{5}{|c|}{ Molecular imaging } \\
\hline $\begin{array}{l}\text { Yezhelyev et al. } \\
{[25], 2007}\end{array}$ & $\begin{array}{l}\text { QD-HER2 }(525 \mathrm{~nm}), \\
\text { QD-ER }(565 \mathrm{~nm}), \\
\text { QD-PR }(605 \mathrm{~nm}), \\
\text { QD-EGFR }(655 \mathrm{~nm}), \\
\text { QD-mTOR }(705 \mathrm{~nm})\end{array}$ & $\begin{array}{l}\text { QDs can be used for multiplexed and } \\
\text { quantitative detection of tumor biomarkers. }\end{array}$ & $\begin{array}{l}\text { High sensitivity; } \\
\text { Increased resolution; } \\
\text { Decreased } \\
\text { autofluorescence. }\end{array}$ & $\begin{array}{l}\text { Better conjugation } \\
\text { chemistry for } \\
\text { well-controlled } \\
\text { bio-ligand are needed; }\end{array}$ \\
\hline $\begin{array}{l}\text { Mulder et al. [26], } \\
2009\end{array}$ & RGD-conjugated QDs & $\begin{array}{l}\text { QDs readily reveal the angiogenic tumor } \\
\text { vasculature, with the highest angiogenic } \\
\text { activity occurring in the periphery of the } \\
\text { tumor. }\end{array}$ & & $\begin{array}{l}\text { The number of } \\
\text { bio-ligands per } \\
\text { nanoparticle needs to } \\
\text { be characterized }\end{array}$ \\
\hline \multicolumn{5}{|c|}{ Cancer cell imaging } \\
\hline $\begin{array}{l}\text { Tada et al. [27], } \\
2007\end{array}$ & $\begin{array}{l}\text { Trastuzumab-QDs } \\
\qquad(800 \mathrm{~nm})\end{array}$ & $\begin{array}{l}\text { Single breast cancer cell can be observed } \\
\text { with QDs. }\end{array}$ & $\begin{array}{l}\text { High brightness; } \\
\text { Resistance to } \\
\text { photobleachings; }\end{array}$ & $\begin{array}{l}\text { The methods current } \\
\text { used for delivery into } \\
\text { cells are not highly } \\
\text { efficient. }\end{array}$ \\
\hline $\begin{array}{l}\text { Shah et al. [28], } \\
2007\end{array}$ & Bio-conjugated QDs & $\begin{array}{l}\text { Stem cells can be effectively labeled by QDs } \\
\text { during both proliferation and multilineage } \\
\text { differentiation for long term. }\end{array}$ & $\begin{array}{l}\text { InP/ZnS QDs are } \\
\text { nontoxic. }\end{array}$ & $\begin{array}{l}\text { It is difficult to } \\
\text { prepare InP/ZnS QDs } \\
\text { because of the } \\
\text { sensitivity of }\end{array}$ \\
\hline $\begin{array}{l}\text { Yong et al. [29], } \\
2009\end{array}$ & $\begin{array}{l}\text { Bio-conjugated } \\
\text { InP/ZnS QDs }\end{array}$ & $\begin{array}{l}\text { InP/ZnS QDs can be used as } \\
\text { non-cadmium-based safe and efficient } \\
\text { optical imaging nanoprobes. }\end{array}$ & & $\begin{array}{l}\text { precursors and } \\
\text { surfactants toward the } \\
\text { reaction environment } \\
\text { in obtaining good InP } \\
\text { QDs }\end{array}$ \\
\hline
\end{tabular}

Cancer tissue imaging

\begin{tabular}{|c|c|c|c|c|}
\hline $\begin{array}{l}\text { Chen et al. [30], } \\
2009\end{array}$ & HER2-QDs & $\begin{array}{l}\text { The expression of Her } 2 \text { of human breast } \\
\text { cancer tissue was detected. }\end{array}$ & $\begin{array}{l}\text { Highly efficient, } \\
\text { nontoxic, quantitative, } \\
\text { sensitive, convenient. }\end{array}$ & $\begin{array}{l}\text { Data from clinical } \\
\text { trials about QDs } \\
\text { comparing with } \\
\text { "Gold standard" is } \\
\text { required. }\end{array}$ \\
\hline
\end{tabular}

\begin{tabular}{|c|c|c|c|c|}
\hline \multicolumn{5}{|c|}{ Animal model imaging } \\
\hline $\begin{array}{l}\text { Smith et al. [31], } \\
2008\end{array}$ & RGD-QDs & $\begin{array}{l}\text { For the first time, authors have } \\
\text { demonstrated the ability to directly follow } \\
\text { the specific binding of nanoparticles to } \\
\text { biomolecules expressed on tumor } \\
\text { neovascular endothelium in mouse model. }\end{array}$ & $\begin{array}{l}\text { Portends the promise of } \\
\text { studying nanoscale } \\
\text { structures interacting } \\
\text { with microscale entities } \\
\text { in living subjects at the } \\
\text { cellular-to-subcellular } \\
\text { level. }\end{array}$ & $\begin{array}{l}\text { The kinetic and } \\
\text { toxicity of QDs in } \\
\text { animal model are still } \\
\text { controversial limiting } \\
\text { the clinical use of } \\
\text { QDs. }\end{array}$ \\
\hline $\begin{array}{l}\text { Parungo et al. } \\
{[32], 2007}\end{array}$ & NIR QDs (840 nm) & $\begin{array}{l}\text { The purpose was to determin whether the } \\
\text { peritoneal space has a predictable lymph } \\
\text { node drainage pattern. Bowel lymphatics are } \\
\text { a key determinant of peritoneal lymph flow, } \\
\text { because bowel resection shifts lymph flow } \\
\text { directly to the intrathoracic lymph nodes via } \\
\text { chest wall lymphatics. }\end{array}$ & $\begin{array}{l}\text { QDs can be excellently } \\
\text { visualized in vivo using } \\
\text { IVM. }\end{array}$ & \\
\hline
\end{tabular}

QDs: quantum dots; Her2: human epidermal growth factor receptor 2; ER: estrogen receptor, PR: progestogen receptor; EGFR: epithelial growth factor receptor; mTOR: mammalian target of rapamycin; RGD: argine-glycine-aspartic aci; NIR: near infrared; IVM: in vivo metric systems.

between the HER2 gene amplification and HER2 protein expression was detected using QD-Abs profiling. This study suggests the possibility of using conjugated QDs to detect low levels of HER2 protein expression, but the clinical relevance of that finding deserves further investigation. To overcome the limitation in the clinical application of those studies aforementioned, we recently used QDs conjugated with antibody for assessment of HER2 status in breast cancer [30].
In our study, 700 patients with invasive breast cancer were enrolled, including 3 males and 697 females. The expression of HER2 in breast cancer was detected in an automated, quantitative, sensitive, and convenient way using our QDsimmunohistochemistry (QDs-IHC) analysis system. Compared with conventional IHC, the QDs-based approach is more sensitive, accurate, and economic, especially for cases of IHC (2+), which indicates that this new method may have 
potentials for clinical application, especially in developing countries (Figure 2).

3.3. Prostate Cancer. Adenocarcinoma of the prostate is the most common cancer for males in the West, with approximately 192,280 new cases and 27,360 deaths form this disease in 2009 in USA alone [1]. Early diagnosis of prostate cancer is based on the prostate-specific antigen (PSA), and the introduction of PSA-based screening has revolutionized prostate cancer detection and ushered in the PSA era in which prostate cancer was detected at an earlier stage and in greater numbers than ever before $[48,49]$. PSA is also an important prognostic marker of prostate cancer [50]. Fluorescent probe conjugated with PSA provides a specific and sensitive tool for early prostate cancer imaging in vivo. With QDs probes conjugated to a PSMA monoclonal antibody $(\mathrm{Ab})$, another marker for prostate cancer diagnosis and therapy, Gao et al. [51] have achieved sensitive and multicolor fluorescence imaging of cancer cells under in vivo conditions. Shi [52] showed the superior quality of QDs, in comparison to IHC, for the detection of androgen receptor (AR) and PSA in prostate cancer cells. Both of those two studies, showing the potential ability of QDs as a diagnosis technology, are good examples to demonstrate why QDs are promising nanoparticles for diagnostic applications [53]. In another study, Gao et al. [54] demonstrated the potential of QDs as a new diagnosis technology for metastasis prostate cancer. Usually, antibodies conjugated to QDs are full-length antibody, which leads to dramatically reduced binding activities. Recently a study demonstrated that the use of single-chain antibody fragments (scFvs) conjugated with QDs appears to have a number of advantages, in terms of solubility, activity, ease of preparation and ease of structurebased genetic engineering, which were approved by detecting prostate cancer cells [55]. Barua Rege [56] also developed a new method to identify prostate cancer cells with different phenotype by unconjugated QDs whose trafficking is cancercell-phenotype-dependent.

3.4. Pancreatic Cancer. The mean survival of pancreatic cancer is around 6 months, and less than $5 \%$ of all patients diagnosed with pancreatic cancer survive beyond 5 years $[57,58]$. This dismal scenario is primarily due to the fact that most patients are diagnosed at advanced stage, due to the lack of specific symptoms and limitations in diagnostics [59]. QDs can target the purpose of early diagnosis of pancreatic cancer [60], even at an early stage of development, with the help of proteins/peptides directed against overexpressed surface receptors on the cancer cells/tissues such as the transferring receptor, the antigen claudin- 4 and urokinase plasminogen activator receptor (UPAR) [61].

Qian [62] used CdSe/CdS/ZnS QDs with improved photoluminescence efficiency and stability as optical agent for imaging pancreatic cancer cells using transferring and anti-Claudin-4. Pancreatic cancer specific uptake is also demonstrated using the monoclonal antibody anti-Claudin4. This targeted QDs platform will be further modified to develop early detection imaging tool for pancreatic cancer.
Yong et al. [29] used non-cadmium-based QDs as highly efficient and nontoxic optical probes for imaging live pancreatic cancer cells. Further bioconjugation with pancreatic cancer specific monoclonal antibodies, such as anticlaudin 4, to the functionalized InP/ZnS QDs, allowed specific in vitro targeting of pancreatic cancer cell lines. The receptor-mediated delivery of the bioconjugates was further confirmed by the observation of poor in vitro targeting in nonpancreatic cancer cell lines without claudin-4receptor. These observations suggest the immense potential of InP/ZnS QDs as non-cadmium-based safe and efficient optical imaging nanoprobes in diagnostic imaging.

\section{QDs-Based Detection of Cancer Metastasis}

Metastasis is a complex, multistep process by which primary tumor cells invade adjacent tissue, enter the systemic circulation (intravasate), translocate through the vasculature, arrest in distant capillaries, extravasate into the surrounding tissue parenchyma, and finally proliferate from microscopic growths (micrometastases) into macroscopic secondary tumors [63]. Over the past 30 years, the study of cancer metastasis has grown exponentially, and a thorough historical review of the field by the late Leonard Weiss has been published [64], but the process of metastasis is still invisible. The vast majority of patients present with locally advanced or distant metastatic disease, rendering their malignancy surgically inoperable [65]. As the origins of the invasive and metastatic phenotypes of carcinoma cells have been the subjects of intense investigation [66], a new model for visualizing the metastasis is needed. QDs-based technology shows advantages in detecting metastasis [67].

4.1. Blood-Born Metastasis to the Lungs. Most of the studies published in literature are focused on breast cancer and prostate cancer, and there is almost no report on the molecular imaging of hepatocellular carcinoma (HCC), especially HCC lung metastasis. HCC is the sixth most common cancer worldwide in terms of numbers of cases $(626,000$ or $5.7 \%$ of new cancer cases), but the number of deaths is almost the same $(598,000)$ due to the very poor prognosis [68]. Disease that is diagnosed at an advanced stage or with progression after locoregional therapy has a dismal prognosis, owing to the underlying liver disease, lack of effective treatment options and metastasis at early stage $[69,70]$. It is documented that $82 \%$ of cases (and deaths) are in developing countries (55\% in china alone) [57], but the incidence is also increasing in developed regions including Japan, West Europe, and the United States [71]. Alpha-fetoprotein (AFP) is an important tumor marker for HCC [72-74]. In our prior study, we used CdSe/ZnS QDs with emission wavelength of $590 \mathrm{~nm}$ (QDs $590)$ linked to AFP monoclonal antibody $(\mathrm{Ab})$ as a probe for fluorescence spectral analysis of HCC $[75,76]$. In another study [77], we tested the biocompatibility, hemodynamics, tissues distribution of the QDs-AFP-Ab probes, and studied the imaging of HCC and its metastasis in vitro and in vivo. Our results indicate that such QDs-based probes have good 

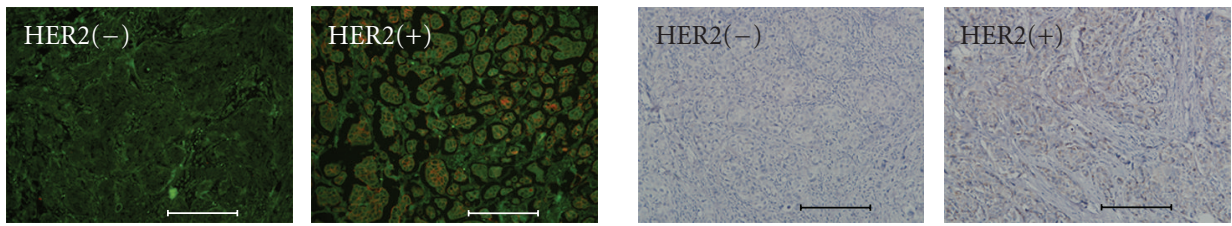

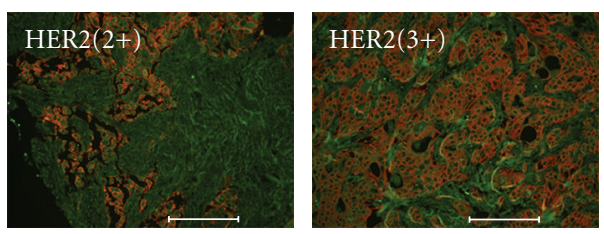

(a)

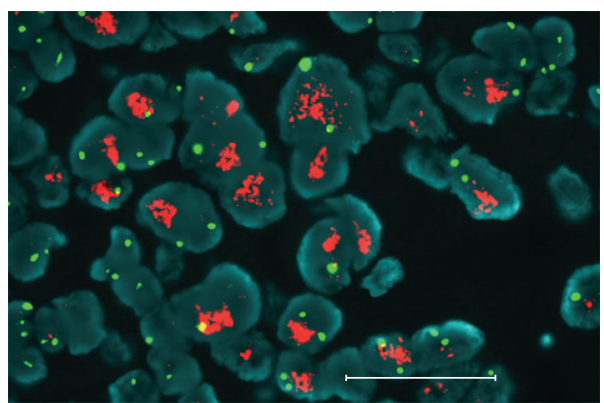

(c)

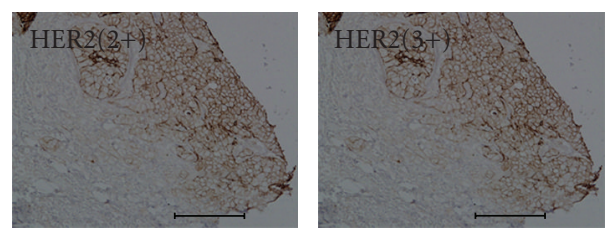

(b)

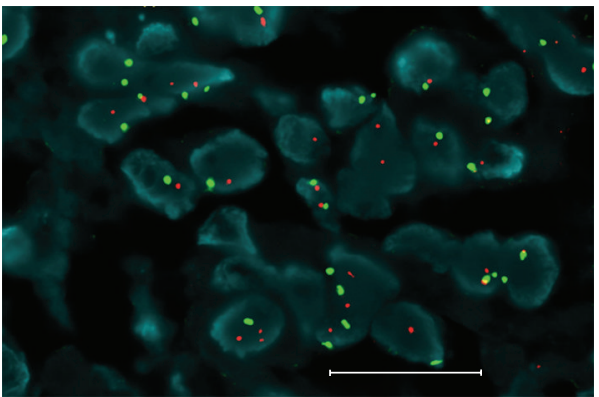

(d)

FIgURE 2: Accurate HER2 testing by QDs-IHC. (a) Specimens with difference HER2 IHC cores detected by QDs-IHC. (b) Control for (a) by conventional IHC (c) and (d) FISH positive (c) and negative (d). Scale bar, $100 \mu \mathrm{m}$ for (a) and (b), $20 \mu \mathrm{m}$ for (c) and (d). (Work from [30].)

stability, specificity and biocompatibility for ultrasensitive fluorescence imaging of molecular targets in our liver cancer model system (Figure 3 ).

4.2. Lymph Node Metastasis. Lymph metastasis is a major route of cancer progression. The state of lymph node draining from the tumor is essential for the diagnosis and therapy of cancer and has major prognostic implications $[78,79]$. Sentinel lymph node (SLN) is much more likely to contain metastatic tumor cells than other lymph nodes in the same region. Among the various methods for SLN diagnosis, QDs have received increasing attention as lymph node delivery agents [80], and Kim [81] was the first to detect animal model SLN as deep as $1 \mathrm{~cm}$ subcutaneously. Nearinfrared QDs are characterized by good tissue penetration and lower background, which are suitable for lymph node metastasis diagnosis [82, 83]. Ballou et al. [84] demonstrated that the QDs injected into two model tumors rapidly migrate to sentinel lymph nodes. Passage from the tumor through lymphatics to adjacent nodes could be visualized dynamically through the skin, and at least two nodes could be defined. Imaging during necropsy confirmed confinement of the QDs to the lymphatic system and demonstrated easy tagging of sentinel lymph nodes for pathology. In addition, examination of the sentinel nodes showed that at least some contained metastatic tumor foci.

The axillary nodal status is the most powerful prognostic factor for early stage breast cancer $[85,86]$. Breast cancer patients routinely undergo surgical staging of the axilla because other primary tumor features are inadequate in predicting the presence versus absence of nodal positivity $[87,88]$. Besides identifying the SLN of breast cancer [89], the state of lymph node draining from esophageal cancer was diagnosed successfully with near-infrared QDs, too [90]. Kobayashi [91] visualized migration of QD-labeled melanoma cells within draining lymphatics. This technique could enable better understanding of lymph node metastasis.

\section{Metabolism and Toxicity}

QDs are promising novel nanoparticles for in vivo biomedical application. To assess their usefulness, it is important to characterize their behavior in vivo, rather than rely on ex vivo measurements and theoretical considerations alone [92]. One obstacle to the in vivo study of QDs is the nonspecific uptake by reticuloendothelial system (RES) including the liver, spleen and lymph system. Particle size, surface coating and PEG-gylation influence the biodistribution of QDs. Nonspecific uptake can be decreased significantly by modifying the surface of QDs with appropriate coat/polymer, which results to prolonged plasma half-self [93-95]. In another way, Jayagopal and his colleagues [96] increased the in vivo circulation time and targeting efficiency by synthesizing QDs incorporating PEG crosslinkers and Fcshielding $\mathrm{mAb}$ fragments. Comparison of the timecourse of fluorescence from Fc-shielded and non-Fc-shielded bioconjugates indicated nonspecific uptake and increased clearance of the non-Fc-shielded QD-mAb. This combination of QD 


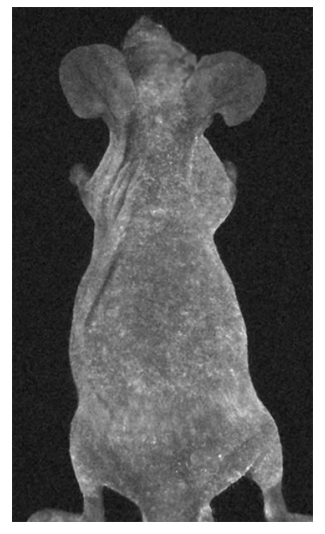

(a)

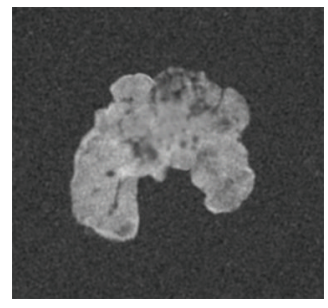

(c)

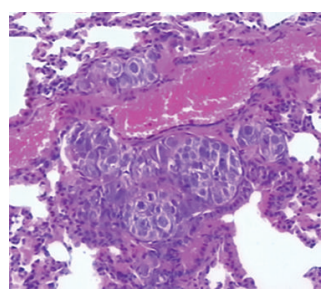

(e)

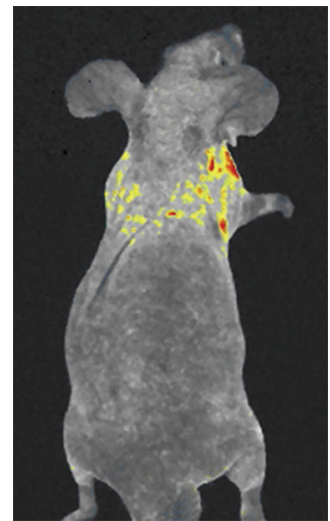

(b)

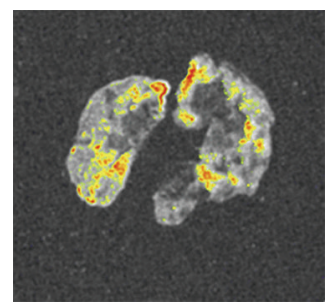

(d)

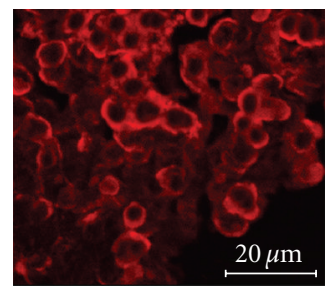

(f)

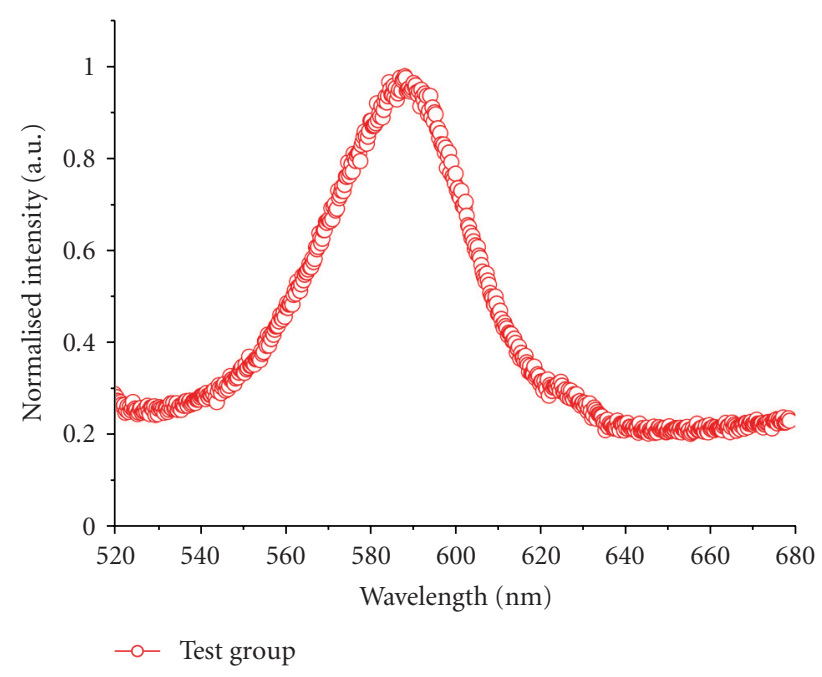

(g)

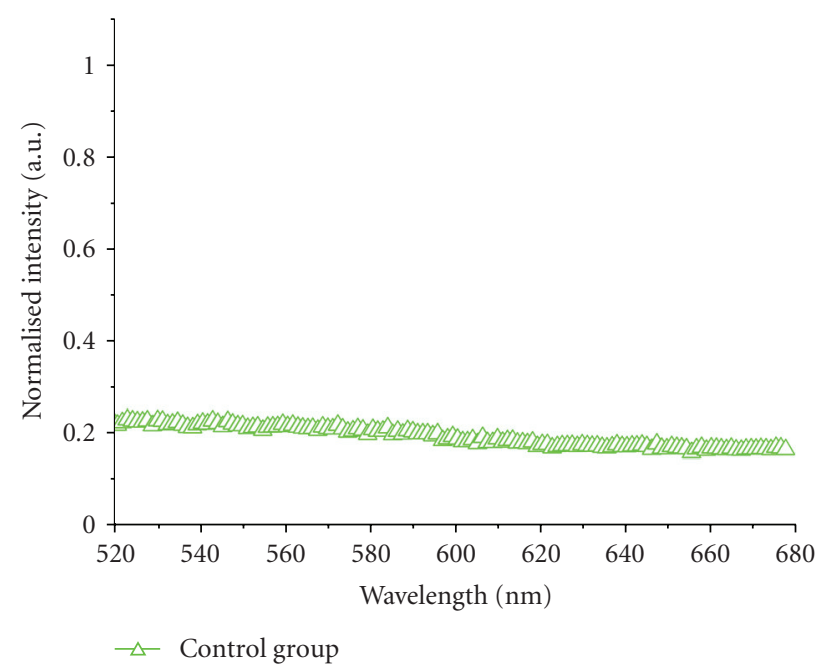

(h)

FIGURE 3: In vivo targeting and imaging of lung metastasis model with QD-AFP-Ab probes. (a) and (b) As compared with the control group (a), the whole body imaging showed that the QD fluorescence was localized in the lung metastases of the model (b). (c, d) As compared with the control group (c), the lung-imaging also showed that there was bright fluorescence in the lung metastases (d). (e) Microphotography of tumor metastasis to lungs, replacing the normal lung tissue with massive tumor cells obviously (HE stain, 200). (f) The confocal microscopic imaging of tumor metastasis to lungs, which showed the specific binding of QD-AFP-Ab probes to tumor cells. Scale bar: $20 \mathrm{~mm}$. (g) and (h) The spectra analysis of the test group (g) and the control group (h) showed that the fluorescence spectra of metastases in the test group were the same with those of QD-AFP-Ab probes, but there was no characteristic $590 \mathrm{~nm}$ peak of the QD at those in the control group. (Work from [77].)

surface design elements offers a promising new in vivo approach to specifically label vascular cell and biomolecules of interest. The in vivo distribution and metabolism of QDs have been studied in some researches, which showed that QDs were generally localized in liver, kidney, spleen, and lung [97-101]. However, there was no universal conclusion about the pathway of QDs clearance and its influence factors. Chen et al. [102] demonstrated that the metabolic pathway of QDs were closely correlated to their aggregation states, and three metabolic pathways were disclosed after intravenous injection: (1) the QDs that maintained their original nanosize without binding in vivo can be rapidly excreted via the kidney; (2) some QDs binding to proteins were translocated to the liver and excreted with feces; (3) an even smaller fraction of the QDs aggregated to larger particles and were retained in liver tissue for long time.

The most obvious challenge to QDs clinical use is the toxicity as most QDs contained heavy metal such as $\mathrm{Cd} 2+$. Release of Cd2+ from QDs will result to heavy metal toxicity, which limited the use of QDs. But it is still a controversy. Cho et al. [103] assessed the intracellular $\mathrm{Cd} 2+$ concentration in human breast cancer MCF-7 cells treated with cadmium telluride (CdTe) and core/shell cadmium selenide/zinc sulfide (CdSe/ZnS) nanoparticles capped with mercaptopropuonic acid (MPA), cysteamine (Cys), or N-acetylcysteine (NAC) conjugated to cysteamine. In cells incubated with CdTe QDs, 
the $\mathrm{Cd} 2+$ concentration determined by a $\mathrm{Cd} 2+$ specific cellular assay ranged from 30 to $150 \mathrm{~nm}$, depending on the capping molecule. A cell viability assay revealed that CdSe/ZnS QDs were nontoxic, where the CdTe QDs were cytotoxic. However, for the various CdTe QDs samples, there was no dose-dependent correlation between cell viability and intracellular $[\mathrm{Cd} 2+]$, implying that their cytotoxicity cannot be attributed solely to the toxic effect of free $\mathrm{Cd} 2+$. CdTe QDs capped with small organic ligands are cytotoxic, core shell CdSe/ZnS QDs present little damaging effects to cells. Those findings conform to with the consensus that the toxicity of QDs is not only Cd-dependent, but affected by many other factors including the size, surface charge, concentration, coat, oxidation, photo-degradation of QDs [104-107]. When injected into Xenopus embryos, the QDs were stable, and embryos displayed an unaltered phenotype and their health was similar to that of uninjected embryos $\left(2 \times 10^{9} \mathrm{QDs} / \mathrm{cell}\right)$. At higher injection concentration $(5 \times$ $10^{9}$ QDs/cell), abnormalities became apparent which may result from changes in the osmotic equilibrium of the cell [21]. Lovric et al. [108] founded out that the size of QDs contributes to their subcellular distribution and pretreatment of cells with the antioxidant $\mathrm{N}$-acetylcysteine and with bovine serum albumin, but not Trolox, significantly reduced the QD-induced cell death. QDs induce cell death via mechanisms involving both $\mathrm{Cd} 2+$ and reactive oxygen species (ROS) accompanied by lysosomal enlargement and intracellular redistribution [109]. Other mechanisms of cell death induced by QDs have been revealed. In a study focused on the cellular calcium homeostasis dysregulation caused by QDs [110], it was found that unmodified QDs can induce neuron death dose dependently, via two possible mechanisms: (a) elevated cytoplasmic calcium levels for an extended period by QDs treatment, due to both extracellular calcium influx and internal calcium release from endoplasmic reticulum; and (b) QDs treatment enhanced activation and inactivation of I-Na, prolonged the time course of activation, slowed I-Na recovery, and reduced the fraction of available voltage-gated sodium channel (VGSC). Therefore, although QDs provide potential invaluable benefit, there are still biosafety considerations for in vivo imaging clinically.

\section{Future Perspectives}

It is clear that as biocompatible QDs are developed they will make powerful basic probes and research tools, and the delivery of QDs/QD biocomjugates is strongly affected by the nature of both the QDs conjugates and the cell types utilized [111]. A lot of techniques about QDs have been improved with the development of new QDs, major issues need to be resolved in the near future. (1) As surface and function modification endue QDs more advantages, QDs become too large for medical imaging with the diameter up to $100 \mathrm{~nm}$; (2) For the stereospecific blockade effect, it is not clear how many functional molecules can conjugate to one QD, which hold back the quantification in molecular detection. (3) FRET is based on individual QDs for QDs deep in aggregation cannot be acting as energy donor, how to avoid the aggregation of QDs in vivo is an important practical issue; (4) More studies on the toxicity of QDs are needed $[53,112-115]$. (5) For the ethics reason, there is no clinical trail of QDs with large samples. Though it is revealed that QDs are stable in animal $[98,102,116]$, more research about kinetics and toxicity of QDs in human are needed before extensive application for clinical diagnosis and therapy [103].

Since the first report about the application of QDs in biology in 1998, there has been no doubt about the advantages of QDs for long fluorescence time and photostability [117]. QDs offer a powerful new tool for illuminating the complex labyrinth of signal transduction pathways and uncovering the intricacies of biomolecular interaction within cells. Remarkably, QDs-base intracellular probes have advantages concurrently with superresolution optical imaging techniques, a combination of the two techniques promises to reveal the mysteries of cellular biology in unprecedented detail $[17,118,119]$. As much technologies based on QDs such as FISH, FRET, and BRET will provide an opportunity for optimizing the treatment of cancer. Cancer therapy will be influenced by QDs significantly. The National Institutes Health (NIH) and the National Nanotechnology Initiative (NNI) are investing into nanomedicine in general and resolving QD toxicity issues for medical applications in particular [120-122]. The NIH expects that over half of the biomedical advances by 2010 will be in the nanotechnology sector, and by that time, the projected market growth for molecular imaging is $\$ 45$ billion [121]. The most promising applications of QDs in cancer are tumor detection, tissue imaging, intracellular imaging, immunohistochemistry, multiplexed diagnostics, and fluoroimmunoassays. All in all, the potential of QDs is immense and would shed a new light on various medical applications.

In summary, the use of QDs in cancer investigations has increased dramatically due to their unique size-dependent optical properties. Bioconjugated near-infrared QDs probes are highly sensitive molecular imaging tools for in vivo study. Further development of QDs might enable their application in detecting and localizing metastasis, quantitative measurement of molecular targets to facilitate targeted therapy, tracking drug delivery, and monitoring the efficacy of therapeutics noninvasively in real time.

\section{Acknowledgments}

This research was supported by the grants from the NewCentury Excellent Talents Supporting Program of the Ministry of Education of China (no. NCET-04-0669), the Natural Science Foundation of China (no. 20675058), the Science Fund for Creative Research Groups of the National Natural Science Foundation of China (no. 20621502).

\section{References}

[1] A. Jemal, R. Siegel, E. Ward, Y. Hao, J. Xu, and M. J. Thun, "Cancer statistics, 2009," CA: A Cancer Journal for Clinicians, vol. 59, no. 4, pp. 225-249, 2009.

[2] R. M. Hoffman, "The multiple uses of fluorescent proteins to visualize cancer in vivo," Nature Reviews Cancer, vol. 5, no. 10, pp. 796-806, 2005. 
[3] R. M. Hoffman, "Imaging cancer dynamics in vivo at the tumor and cellular level with fluorescent proteins," Clinical and Experimental Metastasis, vol. 26, no. 4, pp. 345-355, 2009.

[4] National Cancer Institute, Cancer Nanotechnology Plan, http://nano.cancer.gov/about-alliance/cancernanotechnologyplan.asp.

[5] P. D. Cozzoli, T. Pellegrino, and L. Manna, "Synthesis, properties and perspectives of hybrid nanocrystal structures," Chemical Society Reviews, vol. 35, no. 11, pp. 1195-1208, 2006.

[6] P. S. Nair, K. P. Fritz, and G. D. Scholes, "Evolutionary shape control during colloidal quantum-dot growth," Small, vol. 3, no. 3, pp. 481-487, 2007.

[7] U. Resch-Genger, M. Grabolle, S. Cavaliere-Jaricot, R. Nitschke, and T. Nann, "Quantum dots versus organic dyes as fluorescent labels," Nature Methods, vol. 5, no. 9, pp. 763775, 2008.

[8] J. L. Pelley, A. S. Daar, and M. A. Saner, "State of academic knowledge on toxicity and biological fate of quantum dots," Toxicological Sciences, vol. 112, no. 2, pp. 276-296, 2009.

[9] K. Manzoor, S. Johny, D. Thomas, S. Setua, D. Menon, and S. Nair, "Bio-conjugated luminescent quantum dots of doped ZnS: a cyto-friendly system for targeted cancer imaging," Nanotechnology, vol. 20, no. 6, Article ID 065102, 2009.

[10] X. Michalet, F. F. Pinaud, L. A. Bentolila, et al., "Quantum dots for live cells, in vivo imaging, and diagnostics," Science, vol. 307, no. 5709, pp. 538-544, 2005.

[11] S. M. Reimann and M. Manninen, "Electronic structure of quantum dots," Reviews of Modern Physics, vol. 74, no. 4, pp. 1283-1342, 2002.

[12] A. Gokarna, L.-H. Jin, J. S. Hwang, et al., "Quantum dot-based protein micro- and nanoarrays for detection of prostate cancer biomarkers," Proteomics, vol. 8, no. 9, pp. 1809-1818, 2008.

[13] F. Marchal, E. Pic, T. Pons, B. Dubertret, L. Bolotine, and F. Guillemin, "Quantum dots in oncological surgery: the future for surgical margin status?" Bulletin du Cancer, vol. 95, no. 12, pp. 1149-1153, 2008.

[14] K. C. Weng, C. O. Noble, B. Papahadjopoulos-Sternberg, et al., "Targeted tumor cell internalization and imaging of multifunctional quantum dot-conjugated immunoliposomes in vitro and in vivo," Nano Letters, vol. 8, no. 9, pp. 2851-2857, 2008.

[15] M. Zhou and I. Ghosh, "Quantum dots and peptides: a bright future together," Biopolymers, vol. 88, no. 3, pp. 325-339, 2007.

[16] F. Erogbogbo, K.-T. Yong, I. Roy, G. X. Xu, P. N. Prasad, and M. T. Swihart, "Biocompatible luminescent silicon quantum dots for imaging of cancer cells," ACS Nano, vol. 2, no. 5, pp. 873-878, 2008.

[17] E. T. Ben-Ari, "Nanoscale quantum dots hold promise for cancer applications," Journal of the National Cancer Institute, vol. 95, no. 7, pp. 502-504, 2003.

[18] A. F. E. Hezinger, J. Tessmar, and A. Gopferich, "Polymer coating of quantum dots-a powerful tool toward diagnostics and sensorics," European Journal of Pharmaceutics and Biopharmaceutics, vol. 68, no. 1, pp. 138-152, 2008.

[19] K.-T. Yong, I. Roy, M. T. Swihart, and P. N. Prasad, "Multifunctional nanoparticles as biocompatible targeted probes for human cancer diagnosis and therapy," Journal of Materials Chemistry, vol. 19, no. 27, pp. 4655-4672, 2009.

[20] I. L. Medintz, H. Mattousi, and A. R. Clapp, "Potential clinical applications of quantum dots," International Journal of Nanomedicine, vol. 3, no. 2, pp. 151-167, 2008.
[21] B. Dubertret, P. Skourides, D. J. Norris, V. Noireaux, A. H. Brivanlou, and A. Libchaber, "In vivo imaging of quantum dots encapsulated in phospholipid micelles," Science, vol. 298, no. 5599, pp. 1759-1762, 2002.

[22] A. M. Smith, S. Dave, S. Nie, L. True, and X. Gao, "Multicolor quantum dots for molecular diagnostics of cancer," Expert Review of Molecular Diagnostics, vol. 6, no. 2, pp. 231-244, 2006.

[23] H. Zhang, D. Yee, and C. Wang, "Quantum dots for cancer diagnosis and therapy: biological and clinical perspectives," Nanomedicine, vol. 3, no. 1, pp. 83-91, 2008.

[24] A. M. Smith, H. Duan, A. M. Mohs, and S. Nie, "Bioconjugated quantum dots for in vivo molecular and cellular imaging," Advanced Drug Delivery Reviews, vol. 60, no. 11, pp. 1226-1240, 2008.

[25] M. V. Yezhelyev, A. Al-Hajj, C. Morris, et al., "In situ molecular profiling of breast cancer biomarkers with multicolor quantum dots," Advanced Materials, vol. 19, no. 20, pp. 31463151, 2007.

[26] W. J. M. Mulder, K. Castermans, J. R. van Beijnum, et al., "Molecular imaging of tumor angiogenesis using $\alpha \mathrm{v} \beta 3$ integrin targeted multimodal quantum dots," Angiogenesis, vol. 12, no. 1, pp. 17-24, 2009.

[27] H. Tada, H. Higuchi, T. M. Wanatabe, and N. Ohuchi, "In vivo real-time tracking of single quantum dots conjugated with monoclonal anti-HER2 antibody in tumors of mice," Cancer Research, vol. 67, no. 3, pp. 1138-1144, 2007.

[28] B. S. Shah, P. A. Clark, E. K. Moioli, M. A. Stroscio, and J. J. Mao, "Labeling of mesenchymal stem cells by bioconjugated quantum dots," Nano Letters, vol. 7, no. 10, pp. 3071-3079, 2007.

[29] K. T. Yong, H. Ding, I. Roy, et al., "Imaging pancreatic cancer using bioconjugated inp quantum dots," ACS Nano, vol. 3, no. 3, pp. 502-510, 2009.

[30] C. Chen, J. Peng, H.-S. Xia, et al., "Quantum dots-based immunofluorescence technology for the quantitative determination of HER2 expression in breast cancer," Biomaterials, vol. 30, no. 15, pp. 2912-2918, 2009.

[31] B. R. Smith, Z. Cheng, A. De, A. L. Koh, R. Sinclair, and S. S. Gambhir, "Real-time intravital imaging of RGDquantum dot binding to luminal endothelium in mouse tumor neovasculature," Nano Letters, vol. 8, no. 9, pp. 25992606, 2008.

[32] C. P. Parungo, D. I. Soybel, Y. L. Colson, et al., "Lymphatic drainage of the peritoneal space: a pattern dependent on bowel lymphatics," Annals of Surgical Oncology, vol. 14, no. 2, pp. 286-298, 2007.

[33] H. Lu, B. Li, Y. Kang, et al., "Paclitaxel nanoparticle inhibits growth of ovarian cancer xenografts and enhances lymphatic targeting," Cancer Chemotherapy and Pharmacology, vol. 59, no. 2, pp. 175-181, 2007.

[34] E. V. S. Høgdall, L. Christensen, S. K. Kjaer, et al., "CA125 expression pattern, prognosis and correlation with serum CA125 in ovarian tumor patients. From The Danish "MALOVA” Ovarian Cancer Study," Gynecologic Oncology, vol. 104, no. 3, pp. 508-515, 2007.

[35] R. W. Tothill, A. V. Tinker, J. George, et al., "Novel molecular subtypes of serous and endometrioid ovarian cancer linked to clinical outcome," Clinical Cancer Research, vol. 14, no. 16, pp. 5198-5208, 2008.

[36] Y. Zheng, D. Katsaros, S. J. C. Shan, et al., "A multiparametric panel for ovarian cancer diagnosis, prognosis, and response to chemotherapy," Clinical Cancer Research, vol. 13, no. 23, pp. 6984-6992, 2007. 
[37] H.-Z. Wang, H.-Y. Wang, R.-Q. Liang, and K.-C. Ruan, "Detection of tumor marker CA125 in ovarian carcinoma using quantum dots," Acta Biochimica et Biophysica Sinica, vol. 36, no. 10, pp. 681-686, 2004.

[38] B. B. Nathwani, M. Jaffari, A. R. Juriani, A. B. Mathur, and K. E. Meissner, "Fabrication and characterization of silk-fibroin-coated quantum dots," IEEE Transactions on Nanobioscience, vol. 8, no. 1, pp. 72-77, 2009.

[39] X. Wu, H. Liu, J. Liu, et al., "Immunofluorescent labeling of cancer marker Her2 and other cellular targets with semiconductor quantum dots," Nature Biotechnology, vol. 21, no. 1, pp. 41-46, 2003.

[40] L. Harris, H. Fritsche, R. Mennel, et al., "American society of clinical oncology 2007 update of recommendations for the use of tumor markers in breast cancer," Journal of Clinical Oncology, vol. 25, no. 33, pp. 5287-5312, 2007.

[41] D. J. Slamon, W. Godolphin, L. A. Jones, et al., "Studies of the HER-2/neu proto-oncogene in human breast and ovarian cancer," Science, vol. 244, no. 4905, pp. 707-712, 1989.

[42] A. Goldhirsch, J. H. Glick, R. D. Gelber, A. S. Coates, B. Thurlimann, and H. J. Senn, "Meeting highlights: international expert consensus on the primary therapy of early breast cancer 2005," Annals of Oncology, vol. 16, no. 10, pp. 1569-1583, 2005.

[43] M. M. Moasser, "The oncogene HER2: its signaling and transforming functions and its role in human cancer pathogenesis," Oncogene, vol. 26, no. 45, pp. 6469-6487, 2007.

[44] H. Tsuda, "HER-2 (c-erbB-2) test update: present status and problems," Breast Cancer, vol. 13, no. 3, pp. 236-248, 2006.

[45] A. C. Wolff, M. E. H. Hammond, J. N. Schwartz, et al., "American Society of Clinical Oncology/College of American Pathologists guideline recommendations for human epidermal growth factor receptor 2 testing in breast cancer," Journal of Clinical Oncology, vol. 25, no. 1, pp. 118-145, 2007.

[46] S. Li-Shishido, T. M. Watanabe, H. Tada, H. Higuchi, and N. Ohuchi, "Reduction in nonfluorescence state of quantum dots on an immunofluorescence staining," Biochemical and Biophysical Research Communications, vol. 351, no. 1, pp. 7$13,2006$.

[47] Y. Xiao, X. Gao, G. Gannot, et al., "Quantitation of HER2 and telomerase biomarkers in solid tumors with IgY antibodies and nanocrystal detection," International Journal of Cancer, vol. 122, no. 10, pp. 2178-2186, 2008.

[48] S. J. Freedland, J. M. Hotaling, N. J. Fitzsimons, et al., "PSA in the new millennium: a powerful predictor of prostate cancer prognosis and radical prostatectomy outcomes-results from the SEARCH database," European Urology, vol. 53, no. 4, pp. 758-766, 2008.

[49] M. Noguchi, T. A. Stamey, J. E. McNeal, and C. M. Yemoto, "Preoperative serum prostate specific antigen does not reflect biochemical failure rates after radical prostatectomy in men with large volume cancers," Journal of Urology, vol. 164, no. 5, pp. 1596-1600, 2000.

[50] R. A. Smith, V. Cokkinides, and O. W. Brawley, "Cancer screening in the United States, 2009: a review of current American Cancer Society guidelines and issues in cancer screening," CA: A Cancer Journal for Clinicians, vol. 59, no. 1, pp. 27-41, 2009.

[51] X. Gao, Y. Cui, R. M. Levenson, L. W. K. Chung, and S. Nie, "In vivo cancer targeting and imaging with semiconductor quantum dots," Nature Biotechnology, vol. 22, no. 8, pp. 969976, 2004.

[52] C. Shi, G. Zhou, Y. Zhu, et al., "Quantum dots-based multiplexed immunohistochemistry of protein expression in human prostate cancer cells," European Journal of Histochemistry, vol. 52, no. 2, pp. 127-134, 2008.

[53] H. M. E. Azzazy, M. M. H. Mansour, and S. C. Kazmierczak, "Nanodiagnostics: a new frontier for clinical laboratory medicine," Clinical Chemistry, vol. 52, no. 7, pp. 1238-1246, 2006.

[54] X. Gao, L. W. K. Chung, and S. Nie, "Quantum dots for in vivo molecular and cellular imaging," Methods in Molecular Biology, vol. 374, pp. 135-145, 2007.

[55] Y. Wang, A. M. Dossey, J. W. Froude II, et al., "PSA fluoroimmunoassays using anti-PSA ScFv and quantum-dot conjugates," Nanomedicine, vol. 3, no. 4, pp. 475-483, 2008.

[56] S. Barua and K. Rege, "Cancer-cell-phenotype-dependent differential intracellular trafficking of unconjugated quantum dots," Small, vol. 5, no. 3, pp. 370-376, 2009.

[57] R. H. Hruban, A. Maitra, S. E. Kern, and M. Goggins, "Precursors to pancreatic cancer," Gastroenterology Clinics of North America, vol. 36, no. 4, pp. 831-849, 2007.

[58] S. L. Swierczynski, A. Maitra, S. C. Abraham, et al., "Analysis of novel tumor markers in pancreatic and biliary carcinomas using tissue microarrays," Human Pathology, vol. 35, no. 3, pp. 357-366, 2004.

[59] X. Montet, R. Weissleder, and L. Josephson, "Imaging pancreatic cancer with a peptide-nanoparticle conjugate targeted to normal pancreas," Bioconjugate Chemistry, vol. 17, no. 4, pp. 905-911, 2006.

[60] L. Yang, H. Mao, Y. A. Wang, et al., "Single chain epidermal growth factor receptor antibody conjugated nanoparticles for in vivo tumor targeting and imaging," Small, vol. 5, no. 2, pp. 235-243, 2009.

[61] L. Yang, H. Mao, Z. Cao, et al., "Molecular imaging of pancreatic cancer in an animal model using targeted multifunctional nanoparticles," Gastroenterology, vol. 136, no. 5, pp. 1514-1525, 2009.

[62] J. Qian, K.-T. Yong, I. Roy, et al., "Imaging pancreatic cancer using surface-functionalized quantum dots," Journal of Physical Chemistry B, vol. 111, no. 25, pp. 6969-6972, 2007.

[63] I. J. Fidler, "The pathogenesis of cancer metastasis: the 'seed and soil' hypothesis revisited," Nature Reviews Cancer, vol. 3, no. 6 , pp. 453-458, 2003.

[64] L. Weiss, "Metastasis of cancer: a conceptual history from antiquity to the 1990s," Cancer and Metastasis Reviews, vol. 19, no. 3-4, pp. 193-383, 2000.

[65] K.-T. Yong, "Mn-doped near-infrared quantum dots as multimodal targeted probes for pancreatic cancer imaging," Nanotechnology, vol. 20, no. 1, Article ID 015102, 10 pages, 2009.

[66] A. E. Karnoub, A. B. Dash, A. P. Vo, et al., "Mesenchymal stem cells within tumour stroma promote breast cancer metastasis," Nature, vol. 449, no. 7162, pp. 557-563, 2007.

[67] J. Yoo, T. Kambara, K. Gonda, and H. Higuchi, "Intracellular imaging of targeted proteins labeled with quantum dots," Experimental Cell Research, vol. 314, no. 19, pp. 3563-3569, 2008.

[68] D. M. Parkin, F. Bray, J. Ferlay, and P. Pisani, "Global cancer statistics, 2002," CA: A Cancer Journal for Clinicians, vol. 55, no. 2, pp. 74-108, 2005.

[69] J. Bruix and M. Sherman, "Management of hepatocellular carcinoma," Hepatology, vol. 42, no. 5, pp. 1208-1236, 2005.

[70] J. M. Llovet, A. Burroughs, and J. Bruix, "Hepatocellular carcinoma," Lancet, vol. 362, no. 9399, pp. 1907-1917, 2003.

[71] M. B. Thomas and A. X. Zhu, "Hepatocellular carcinoma: the need for progress," Journal of Clinical Oncology, vol. 23, no. 13, pp. 2892-2899, 2005. 
[72] T. Morinaga, M. Sakai, T. G. Wegmann, and T. Tamaoki, "Primary structures of human $\alpha$-fetoprotein and its mRNA," Proceedings of the National Academy of Sciences of the United States of America, vol. 80, no. 15, pp. 4604-4608, 1983.

[73] C. J. P. Smith and P. C. Kelleher, "Alpha-fetoprotein molecular heterogeneity. Physiological correlations with normal growth, carcinogenesis and tumor growth," Biochimica et Biophysica Acta, vol. 605, no. 1, pp. 1-32, 1980.

[74] F. Trevisani, P. E. D’Intino, A. M. Morselli-Labate, et al., "Serum $\alpha$-fetoprotein for diagnosis of hepatocellular carcinoma in patients with chronic liver disease: influence of HBsAg and anti-HCV status," Journal of Hepatology, vol. 34, no. 4, pp. 570-575, 2001.

[75] X. Yu, L. Chen, Y. Deng, et al., "Fluorescence analysis with quantum dot probes for hepatoma under one- and twophoton excitation," Journal of Fluorescence, vol. 17, no. 2, pp. 243-247, 2007.

[76] X. Yu, L. Chen, K. Li, et al., "Immunofluorescence detection with quantum dot bioconjugates for hepatoma in vivo," Journal of Biomedical Optics, vol. 12, no. 1, Article ID 014008, 2007.

[77] L.-D. Chen, J. Liu, X.-F. Yu, et al., "The biocompatibility of quantum dot probes used for the targeted imaging of hepatocellular carcinoma metastasis," Biomaterials, vol. 29, no. 31, pp. 4170-4176, 2008.

[78] K. Dowlatshahi, M. Fan, H. C. Snider, and F. A. Habib, "Lymph node micrometastases from breast carcinoma: reviewing the dilemma," Cancer, vol. 80, no. 7, pp. 11881197, 1997.

[79] H. Kobayashi, S. Kawamoto, M. Bernardo, M. W. Brechbiel, M. V. Knopp, and P. L. Choyke, "Delivery of gadoliniumlabeled nanoparticles to the sentinel lymph node: comparison of the sentinel node visualization and estimations of intra-nodal gadolinium concentration by the magnetic resonance imaging," Journal of Controlled Release, vol. 111, no. 3, pp. 343-351, 2006.

[80] R. Jain, P. Dandekar, and V. Patravale, "Diagnostic nanocarriers for sentinel lymph node imaging," Journal of Controlled Release, vol. 138, no. 2, pp. 90-102, 2009.

[81] S. Kim, Y. T. Lim, E. G. Soltesz, et al., "Near-infrared fluorescent type II quantum dots for sentinel lymph node mapping," Nature Biotechnology, vol. 22, no. 1, pp. 93-97, 2004.

[82] L. A. Bentolila, Y. Ebenstein, and S. Weiss, "Quantum dots for in vivo small-animal imaging," Journal of Nuclear Medicine, vol. 50, no. 4, pp. 493-496, 2009.

[83] K.-T. Yong, I. Roy, H. Ding, E. J. Bergey, and P. N. Prasad, "Biocompatible near-infrared quantum dots as ultrasensitive probes for long-term in vivo imaging applications," Small, vol. 5, no. 17, pp. 1997-2004, 2009.

[84] B. Ballou, L. A. Ernst, S. Andreko, et al., "Sentinel lymph node imaging using quantum dots in mouse tumor models," Bioconjugate Chemistry, vol. 18, no. 2, pp. 389-396, 2007.

[85] A. D. Purushotham, S. Upponi, M. B. Klevesath, et al., "Morbidity after sentinel lymph node biopsy in primary breast cancer: results from a randomized controlled trial," Journal of Clinical Oncology, vol. 23, no. 19, pp. 4312-4321, 2005.

[86] U. Veronesi, G. Paganelli, G. Viale, et al., "Sentinel lymph node biopsy and axillary dissection in breast cancer: results in a large series," Journal of the National Cancer Institute, vol. 91, no. 4, pp. 368-373, 1999.
[87] R. Crane-Okada, R. A. Wascher, D. Elashoff, and A. E. Giuliano, "Long-term morbidity of sentinel node biopsy versus complete axillary dissection for unilateral breast cancer," Annals of Surgical Oncology, vol. 15, no. 7, pp. 19962005, 2008.

[88] G. H. Lyman, A. E. Giuliano, M. R. Somerfield, et al., "American Society of Clinical Oncology guideline recommendations for sentinel lymph node biopsy in early-stage breast cancer," Journal of Clinical Oncology, vol. 23, no. 30, pp. 7703-7720, 2005.

[89] Y. Hama, Y. Koyama, Y. Urano, P. L. Choyke, and H. Kobayashi, "Simultaneous two-color spectral fluorescence lymphangiography with near infrared quantum dots to map two lymphatic flows from the breast and the upper extremity," Breast Cancer Research and Treatment, vol. 103, no. 1, pp. 23-28, 2007.

[90] C. P. Parungo, S. Ohnishi, S.-W. Kim, et al., "Intraoperative identification of esophageal sentinel lymph nodes with nearinfrared fluorescence imaging," Journal of Thoracic and Cardiovascular Surgery, vol. 129, no. 4, pp. 844-850, 2005.

[91] H. Kobayashi, M. Ogawa, N. Kosaka, P. L. Choyke, and Y. Urano, "Multicolor imaging of lymphatic function with two nanomaterials: quantum dot-labeled cancer cells and dendrimer-based optical agents," Nanomedicine, vol. 4, no. 4, pp. 411-419, 2009.

[92] A. M. Mohs, H. W. Duan, B. A. Kairdolf, A. M. Smith, and S. M. Nie, "Proton-resistant quantum dots: stability in gastrointestinal fluids and implications for oral delivery of nanoparticle agents," Nano Research, vol. 2, no. 6, pp. 500508, 2009.

[93] B. Ballou, B. C. Lagerholm, L. A. Ernst, M. P. Bruchez, and A. S. Waggoner, "Noninvasive imaging of quantum dots in mice," Bioconjugate Chemistry, vol. 15, no. 1, pp. 79-86, 2004.

[94] X. Gao, L. Yang, J. A. Petros, F. F. Marshall, J. W. Simons, and S. Nie, "In vivo molecular and cellular imaging with quantum dots," Current Opinion in Biotechnology, vol. 16, no. 1, pp. 6372, 2005.

[95] M. L. Schipper, G. Iyer, A. L. Koh, et al., "Particle size, surface coating, and PEGylation influence the biodistribution of quantum dots in living mice," Small, vol. 5, no. 1, pp. 126134, 2009.

[96] A. Jayagopal, P. K. Russ, and F. R. Haselton, "Surface engineering of quantum dots for in vivo vascular imaging," Bioconjugate Chemistry, vol. 18, no. 5, pp. 1424-1433, 2007.

[97] H. S. Choi, B. I. Ipe, P. Misra, J. H. Lee, M. G. Bawendi, and J. V. Frangioni, "Tissue- and organ-selective biodistribution of NIR fluorescent quantum dots," Nano Letters, vol. 9, no. 6, pp. 2354-2359, 2009.

[98] H. S. Choi, W. Liu, P. Misra, et al., "Renal clearance of quantum dots," Nature Biotechnology, vol. 25, no. 10, pp. 1165-1170, 2007.

[99] Y. Inoue, K. Izawa, K. Yoshikawa, H. Yamada, A. Tojo, and K. Ohtomo, "In vivo fluorescence imaging of the reticuloendothelial system using quantum dots in combination with bioluminescent tumour monitoring," European Journal of Nuclear Medicine and Molecular Imaging, vol. 34, no. 12, pp. 2048-2056, 2007.

[100] V. Karabanovas, E. Zakarevicius, A. Sukackaite, G. Streckyte, and R. Rotomskis, "Examination of the stability of hydrophobic (CdSe)ZnS quantum dots in the digestive tract of rats," Photochemical and Photobiological Sciences, vol. 7, no. 6, pp. 725-729, 2008.

[101] W. Liu, H. S. Choi, J. P. Zimmer, E. Tanaka, J. V. Frangioni, and M. Bawendi, "Compact cysteine-coated CdSe(ZnCdS) 
quantum dots for in vivo applications," Journal of the American Chemical Society, vol. 129, no. 47, pp. 1453014531, 2007.

[102] Z. Chen, H. Chen, H. Meng, et al., "Bio-distribution and metabolic paths of silica coated CdSeS quantum dots," Toxicology and Applied Pharmacology, vol. 230, no. 3, pp. 364-371, 2008.

[103] S. J. Cho, D. Maysinger, M. Jain, B. Roder, S. Hackbarth, and F. M. Winnik, "Long-term exposure to CdTe quantum dots causes functional impairments in live cells," Langmuir, vol. 23, no. 4, pp. 1974-1980, 2007.

[104] W.-H. Chan, N.-H. Shiao, and P.-Z. Lu, "CdSe quantum dots induce apoptosis in human neuroblastoma cells via mitochondrial-dependent pathways and inhibition of survival signals," Toxicology Letters, vol. 167, no. 3, pp. 191-200, 2006.

[105] R. Hardman, "A toxicologic review of quantum dots: toxicity depends on physicochemical and environmental factors," Environmental Health Perspectives, vol. 114, no. 2, pp. 165172, 2006.

[106] H. Li, Q. Zhou, W. Liu, B. Yan, Y. Zhao, and G. Jiang, "Progress in the toxicological researches for quantum dots," Science in China, Series B, vol. 51, no. 5, pp. 393-400, 2008.

[107] A. Anas, H. Akita, H. Harashima, T. Itoh, M. Ishikawa, and V. Biju, "Photosensitized breakage and damage of DNA by CdSe-ZnS quantum dots," Journal of Physical Chemistry B, vol. 112, no. 32, pp. 10005-10011, 2008.

[108] J. Lovric, H. S. Bazzi, Y. Cuie, G. R. A. Fortin, F. M. Winnik, and D. Maysinger, "Differences in subcellular distribution and toxicity of green and red emitting CdTe quantum dots," Journal of Molecular Medicine, vol. 83, no. 5, pp. 377-385, 2005.

[109] M. C. Mancini, B. A. Kairdolf, A. M. Smith, and S. $\mathrm{Nie}$, "Oxidative quenching and degradation of polymerencapsulated quantum dots: new insights into the longterm fate and toxicity of nanocrystals in vivo," Journal of the American Chemical Society, vol. 130, no. 33, pp. 1083610837, 2008.

[110] M. Tang, T. Xing, J. Zeng, et al., "Unmodified CdSe quantum dots induce elevation of cytoplasmic calcium levels and impairment of functional properties of sodium channels in rat primary cultured hippocampal neurons," Environmental Health Perspectives, vol. 116, no. 7, pp. 915-922, 2008.

[111] J. B. Delehanty, H. Mattoussi, and I. L. Medintz, "Delivering quantum dots into cells: strategies, progress and remaining issues," Analytical and Bioanalytical Chemistry, vol. 393, no. 4, pp. 1091-1105, 2009.

[112] J. Drbohlavova, V. Adam, R. Kizek, and J. Hubalek, "Quantum dots-characterization, preparation and usage in biological systems," International Journal of Molecular Sciences, vol. 10, no. 2, pp. 656-673, 2009.

[113] W. A. Hild, M. Breunig, and A. Goepferich, "Quantum dots-nano-sized probes for the exploration of cellular and intracellular targeting," European Journal of Pharmaceutics and Biopharmaceutics, vol. 68, no. 2, pp. 153-168, 2008.

[114] B.-K. Pong, B. L. Trout, and J.-Y. Lee, "Modified ligandexchange for efficient solubilization of CdSe/ZnS quantum dots in water: a procedure guided by computational studies," Langmuir, vol. 24, no. 10, pp. 5270-5276, 2008.

[115] M. A. Walling, J. A. Novak, and J. R. E. Shepard, "Quantum dots for live cell and in vivo imaging," International Journal of Molecular Sciences, vol. 10, no. 2, pp. 441-491, 2009.

[116] Y. Higuchi, M. Oka, S. Kawakami, and M. Hashida, "Mannosylated semiconductor quantum dots for the labeling of macrophages," Journal of Controlled Release, vol. 125, no. 2, pp. 131-136, 2008.

[117] D. J. Bharali, D. W. Lucey, H. Jayakumar, H. E. Pudavar, and P. N. Prasad, "Folate-receptor-mediated delivery of InP quantum dots for bioimaging using confocal and two-photon microscopy," Journal of the American Chemical Society, vol. 127, no. 32, pp. 11364-11371, 2005.

[118] A. M. Smith, A. M. Mohs, and S. Nie, "Tuning the optical and electronic properties of colloidal nanocrystals by lattice strain," Nature Nanotechnology, vol. 4, no. 1, pp. 56-63, 2009.

[119] A. M. Smith and S. Nie, "Next-generation quantum dots," Nature Biotechnology, vol. 27, no. 8, pp. 732-733, 2009.

[120] R. Bawa, "Will the nanomedicine "patent land grab" thwart commercialization?" Nanomedicine: Nanotechnology, Biology, and Medicine, vol. 1, no. 4, pp. 346-350, 2005.

[121] T. Flynn and C. Wei, "The pathway to commercialization for nanomedicine," Nanomedicine: Nanotechnology, Biology, and Medicine, vol. 1, no. 1, pp. 47-51, 2005.

[122] National Nanotechnology Initiative (NNI), http://www.nano .gov. 

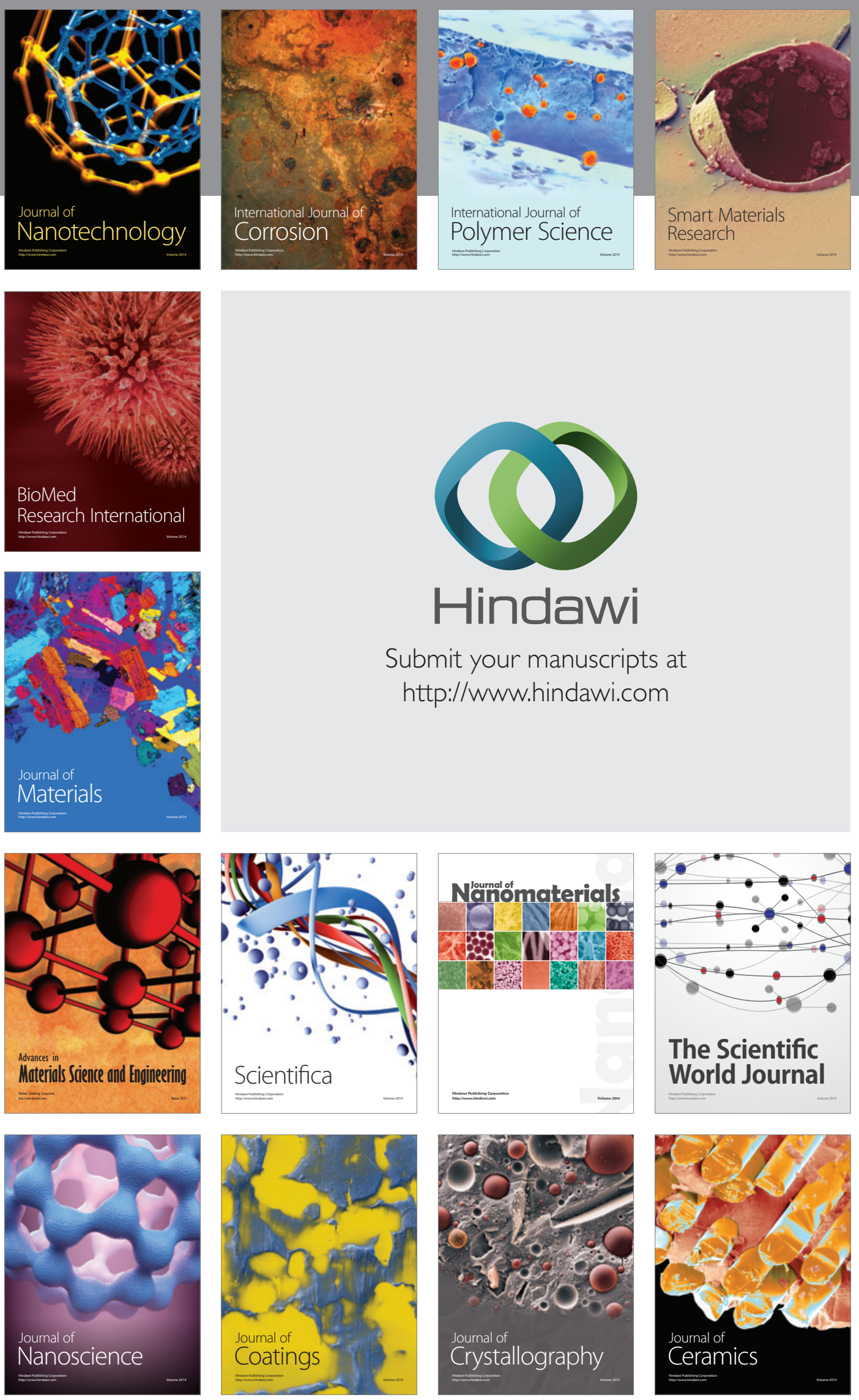

The Scientific World Journal

Submit your manuscripts at

http://www.hindawi.com

\section{World Journal}

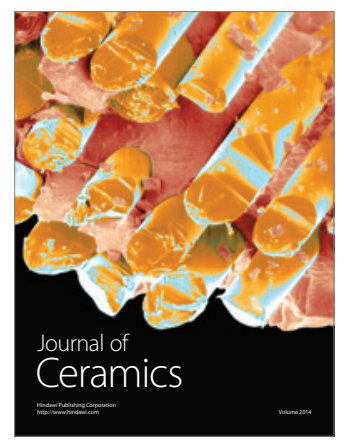

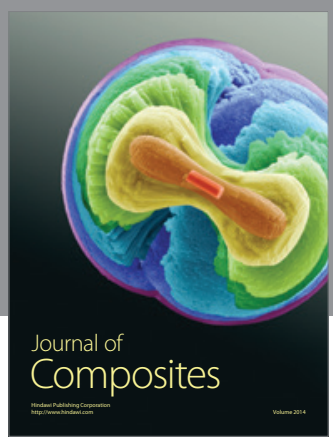
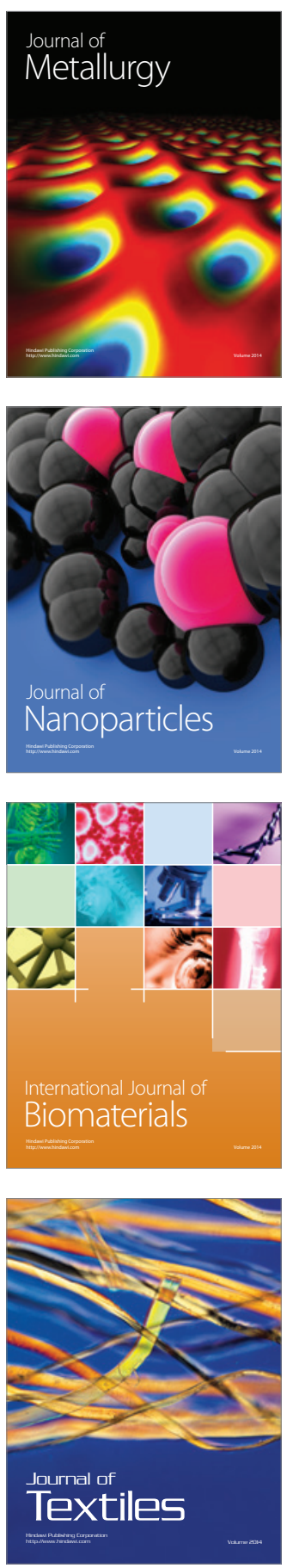